\title{
AN ANALYSIS OF COMPETITIVE CAPABILITIES AND ACCOMMODATION PERFORMANCE FOR SMALL AND MEDIUM- SIZED ACCOMMODATIONS (SMSAs) IN EAST-COAST OF MALAYSIA DURING THE COVID-19 PANDEMIC
}

\author{
Siti Nur 'Atikah Zulkiffli', Siti Falindah Padlee'2, Nur Farah Zafira Zaidi \& Noor Zatul Iffah Hussin ${ }^{4}$ \\ 1,2,3,4Faculty of Business, Economics and Social Development, Universiti Malaysia Terengganu \\ (atikahzulkiffli@umt.edu.my, siti.falindah@umt.edu.my nurfarahzafira@gmail.com, \\ zatul.iffah@umt.edu.my)
}

\begin{abstract}
The COVID -19 pandemic has posed an unprecedented threat to the hospitality industry. Numerous hospitality firms have been impacted by strategies used to flatten the COVID-19 curve. Hospitality firms are required to significantly alter their operations in the COVID-19 business climate in order to secure industry survival and to mitigate the impact of the pandemic. As a result, this study focuses on small and medium-sized accommodations (SMSAs) on Malaysia's East Coast, which are particularly hard hit by the pandemic. The study of SMSAs on Malaysia's East Coast discovered that marketing and human resource management contribute significantly to accommodation performance, while the other two factors have a negligible effect on accommodation performance during this pandemic, as determined by multiple regression analysis.

KEYWORDS: Tourism industry, Competitive capabilities, Orchid rating categories, Resource-based vide, Covid-19 pandemic
\end{abstract}

\section{PURPOSE AND BACKGROUND}

The COVID-19 pandemic is putting many business leaders, entrepreneurs, and employees to the ultimate test. The unprecedented nature of COVID-19 has had crippling effects, resulting in numerous restrictions on businesses, with far-reaching implications on hotels, restaurants, bars, and other hospitality businesses, with overall serious and seemingly insurmountable challenges for the hospitality industry (Gosling et al., 2020).

During the pandemic, SMSAs are suffering with their human resources, information technology, marketing, customer service, and innovation skills. Personnel lack of training will only lead to a reduction in the performance of the accommodations. Therefore, the goal of this study is to see if SMSAs on Malaysia's East Coast can improve their competitive capabilities and accommodation performance in order to improve Malaysia's image of hospitality in the eyes of tourists.

Small and medium-sized accommodations (SMSAs) on Malaysia's East Coast must recognise their potential to compete effectively in local markets. To improve their accommodation performance, SMSAs should concentrate on its marketing management, human resources management, innovation capabilities management, and information technology management. These factors can be examined to determine whether SMSAs have excellent competitive capabilities in the industry. 
Many studies, according to Wall et al. (2004), have requested directors to measure the performance of their businesses using subjective measurement because data can be collected easily using a questionnaire. As a result, this study relies on subjective measurement and focuses on SMSA on Malaysia's East Coast.

\section{METHODOLOGY}

This research employs a quantitative research design. 144 SMSAs from Malaysia's East Coast were studied, including those on the states of Terengganu, Kelantan, and Pahang (MOTAC, 2017). 144 respondents in the study were chosen based on the following criteria:

(a) SMSAs that are members of MOTAC's Orchid Classification Scheme, and

(b) Malaysia's East Coast SMSAs, which include Terengganu, Kelantan, and Pahang.

The survey instrument was tailored to the local tourism environment and validated using face validity. In this study, the SMSAs were sampled using a basic random sampling method. A total of 105 respondents were picked from the sample and were sent questionnaires. One respondent from each SMSA with an executive level or higher was used as the sample for this study.

A total of 97 questionnaires were received, with 100\% of them being suitable for use. This amounts to a response rate of 92.4 percent, which is considered high when compared with previous online mailsurvey studies in Malaysia. There were no missing data because the researchers used Google Forms to make every item mandatory. As a result, respondents were unable to go on to the next question without providing a legitimate response. SPSS Statistics V22 was used to analyse the survey data.

\section{FINDINGS}

Multiple linear regression analysis was used to develop a model for predicting accommodation performance of SMSAs in East-coast of Malaysia from their management aspects (namely, marketing, human resource, innovation capability and information technology). The value of $\mathrm{R}$ is (.386), which indicates a good level of prediction. Also, the coefficient of determination indicates has a value of .149 $\left(R^{2}=.149\right)$ for marketing, human resource, innovation capability and information technology management which explain 14.9 percent of the variability in accommodation performance. Hence, 82.1 percent (100 percent - 14.9 percent) of the variation is caused by factors other than the predictors included in this model.

The results of testing the coefficients to determine the statistical significance of the independent variables. It is clear that two variables - marketing management $(p=.044, p<.05)$ and human resource management $(p=.028, p<.05)$ - contribute statistically to the prediction. Other two factors, innovation capability management and information technology management, contributed by $p=.936, p>.05$ and $p=.854, p>.05$, respectively, have no statistically significant influence on the accommodation performance of SMSAs in Malaysia's east coast. Human resource management ( $\beta=.254)$ has the biggest contribution to understanding accommodation performance, followed by marketing management $(\beta=.215)$.

The model does not have a multicollinearity problem because the variation inflation factor (VIF) for all four variables is less than 10 (or a tolerance greater than.1). The component coefficients of determination for marketing management, human resource management, innovation capability management, and information technology management are $(.196)^{2},(.214)^{2},(-.008)^{2}$, and $(.018)^{2}$, respectively.

When the individual contributions of the predictors are added together, they account for about 8.46 percent of the variation in the outcome variable. The response variable's percentage of variance differs from the model's $R^{2}$ value (14.9 percent). The predictors were responsible for 6.44 percent (14.9 - 8.46) 
of the overlapping predicted accommodation performance. This demonstrates that the overall effect of all variables is highly favourable. As a result, it can be inferred that the links between marketing and human resource management and SMSAs accommodation performance in Malaysia's east coast are statistically significant $(p<.05)$.

\section{CONCLUSION}

In general, this research offered some insight on the hotel business, which has been devastated by recent events. To present, the hotel industry is still undergoing a difficult and trying period following the introduction of MCO. Additionally, the imposition of entrance restrictions and border closures threw the hotel business into a tailspin. This investigation exposed the reality of what hotels are currently suffering as a result of COVID-19.

The purpose of this study is to enhance the performance of small and medium-sized accommodations (SMSAs) on Malaysia's East Coast. The study examines four elements (marketing management, human resource management, innovation capability management, and information technology) that may influence the accommodating performance. The findings of this study differ from those of the prior study.

This study discovered that marketing and human resource management substantially contribute to the accommodation performance of SMSAs on Malaysia's east coast during the pandemic, but the other two components had a negligible effect.

\section{CONTRIBUTION/PRACTICAL IMPLICATIONS}

The small contribution is due to many factors: first, most SMSAs on Malaysia's east coast received less visitors during the pandemic than they did before to the outbreak.

Second, because the majority of them work just for survival, marketing and human resource management, rather than innovative capabilities and information technology, are the primary contributors to their performance.

Finally, because these SMSAs are built on a solid foundation of marketing and human resource management, they can thrive even during a pandemic, as these two elements serve as a pillar of their survival. Indeed, if they are attempting to upgrade their information technology and expand their innovation capabilities, they may require additional capital and a higher pay scale for experts, and this is a nearimpossible task in the midst of a pandemic season.

\section{REFERENCES}

Gössling, S., Scott, D., Hall, C. M. (2020). Pandemics, tourism and global change: A rapid assessment of COVID-19. Journal of Sustainable Tourism, 29(1) 1-20.

MOTAC (2017). Rated Tourist Accommodation Premises. Accessed on 11/09/2017 from http://www. motac.gov.my [].

Wall, T. D., Michie, J., Patterson, M., Wood, S. J., Sheehan, M., Clengg, C. W., \& West, M. (2004). On the validity of subjective measure of company performance. Personnel Psychology, 57(1), 95-118. 